\title{
Component and Structural Analysis of Future Teachers' Preparedness for Scientific and Research Activity
}

\author{
Artemenko E.V. \\ Humanities Department \\ Churapcha State Institute of Physical Culture and \\ Sport \\ Churapcha, Russia \\ ewa_12@mail.ru
}

\author{
Artemenko T.G. \\ Natural Sciences Department \\ Churapcha State Institute of Physical Culture and \\ Sport \\ Churapcha, Russia \\ 2336964@ua.fm
}

\begin{abstract}
The purpose of this article is to make a component and structural analysis of future teachers preparedness for the scientific and research activitity in the context of professional education of future teachers. And also to theoretically explain this problem and work out basic methodological principles of forming scientific competence of a future teacher. Resulting from deep understanding and comparison of different scientific approaches to defining the structure of students' research activity in the university, the authors determined the component structure of future teachers readiness for the scientific research activitity, including motivational-purposeful, personal, operational-activity and reflexive components, each of which is characterized by a certain content. The motivational-purposeful component is represented by a morally valuable attitude to their profession and research work as to a personal value; also it is represented by stimulating research activity. The personal component of future teachers' readiness for the scientific research work consists in recognition of pupil's identity as the supreme pedagogical value and system of personal professional qualities necessary for realizing research activity. The operational-activity component presupposes the maturity of knowledge and skills to apply scientific inquiry methods for successful solution of professional issues and tasks. The reflexive component of future teachers' readiness for scientific work is characterized by demonstration of research activity; perception of oneself as a professional researcher on the basis of self-understanding, self-analysis and self-esteem; selfcontrol of behavior; prognosis of short- and long-term results of their implementation.
\end{abstract}

Keywords - preparedness for the scientific research activitity; future teachers; component and structural analysis; motivationalpurposeful component; personal component; operational-activity component; reflexive component.

\section{INTRODUCTION}

As a modern vitacultural paradigm of education must not only help future teachers to get the required volume of knowledge and skills but also to develop the personality of a specialist-researcher of a whole new type. It is characterized by purposeful-rational behavior, self-understanding, selfimprovement and self-realization - the triad which forms the core of the specialist [9] who has worldview principles, established abstract-logical way of thinking, who is initiative, decisive, energetic, active, able to constantly gain new knowledge and be quick in decisions on the basis of the life philosophy agreed upon with interests of other people, so it is needed to extrapolate these requirements onto the professional development of a future teacher and to understand the necessity of cardinal changes of all the education components including purposes, contents, character in which the personality becomes a subobject of learning activity.

Preparedness for the scientific research activitity is an important element of professional growing and professional rise of a future teacher to the tops of his mastership and competence, it is one of his professional readiness parameters which has major influence on the quality of pedagogical process and results of the specialist's activity. In this regard, investigation of this phenomenon is actual in the context of psycho-pedagogical, philosophical and sociocultural discourse, guarantee of of the future teacher professional activity effectiveness, study of the personality professionalization specificity within the framework of this profession, especially preparation for scientific research activity of the high school learning subjects category mentioned above.

\section{LITERATURE REVIEW}

In the context of our investigation, there appears a necessity to give consideration to the concept "preparedness of future teachers for the scientific and research activitity" and to carry out its component and structural analysis.

It is important to note that in scientific psychopedagogical literature preparedness of the personality is mainly regarded in the context of professional occupation.

So, N.Kuzmina, V.Slastenin understand professional readiness as a complex formation which consists of cognitive, motivational and emotional-volitional components; as a range of knowledge and skills and professionally important personality qualities, which a specialist should posess for the successful adaptation to activity. [10],[20]; K.Platonov - as a subjective condition of the personality that realizes oneself capable and prepared to this or that professional occupation and aims at its fulfillment; as a result of labour education, 
professional training, psychological preparation [14, 126]; E. Rapatsevich - as an integrative personal quality of the student and as a precondition for the effective work after graduating from the university [16]; K. Durai-Novakova offers to consider professional readiness for pedagogical activities "as an entire expression of all substructures of the personality oriented toward full and successful execution of different teacher's duties. Thus, professional readiness for pedagogical work appears to be a complex structural formation, the ctentral core of which is positive directives, motives and developed values of the teacher's profession. In addition, we can include in this structure professionally important traits of character, pedagogical abilities, a whole of professional-pedagogical knowledge and skills, certain experience of their practical application. Professional readiness is in unity with orientation towards professional occupation and constant labour directives" [5, 25]; L.Kondrashova explains readiness for pedagogical occupation as a type of complex personal formation which creates a desire to be occupied with pedagogical activity and also as an important indicator of university graduant development [8,7-8]; L.Kutepova - as a complicated structural formation which includes motives, directing to perception of necessity and significance of evaluation and defining a set of professionally conditioned requirements to the teacher's personality and his activity, realization of which ensures success of execution and estimation of their knowledge [11].

All the above mentioned affords ground to consider readiness for professional activity as an entire active-efficient condition of the personality, which ensures professional orientation and successful fulfillment of pedagogical occupation.

It is necessary to note that scientists include more than 50 different components into the structure of readiness (readiness for innovative professional activity, independent research activity, development of research culture, development of research competence etc.). On the one hand, it speaks about heterogeneity of this personal formation and its multidimensional character, on the other - about absence of common approach in the science for determination of the content and structural components of readiness.

In scientific researches on pedagogics we can find explanation of the research competence structure proposed by L.Bondarenko, which to some extent has something in common with the thoughts of predecessors, for instance: motivational and value component (a system of motives and values which determines the directions of teacher's activity for effective execution of research work); gnostic component (a set of methodological, professional, interdisciplinary scientific knowledge and cognitive skills of research activity); practicalactivity component (a set of intellectual, practical, organizational skills and teacher's abilities to carry out research activity effectively); personality-reflexive (creative, professional qualities of the researcher, abilities for selfregulation and self-organization of research activity) [3, c. 56].

It is significant to mention the components of teacher's research culture given by I. Romanovskaya: cognitive (a system of psycho-pedagogical, scientific-research and methodological knowledge), motivational-value (a system of attitudes toward the corresponding type of activity), operational (readiness for practical realization of purposes and objectives) [17].

Scientific works of N. Kuzmina persuasively give evidence that all the components show themselves up in the research activity of any speciality teacher, and for their successful accomplishment the following corresponding skills are required - comminicative, organizational, constructional, perceptual, suggestive, didactic, cognitive, self-regulational and the like.

The author singles out the following interconnected components in the structure of research activity:

- constructional, connected with the selection and composition of teaching and educational material in accordance with age and individual peculiarities of students; planning and building up the pedagogical process; defining the structure of your actions and deeds; designing the training aids supply for carrying out teaching and educational work;

- organizational component calls for engagement of students in different types of activity, organization of student community and transforming it into the instrument of pedagogical impact on the personality;

- communicative component, the essence of which lies in establishing pedagogically rational mutual relationships with students, colleagues, parents, public members [10].

A well-known scientist M. Knyazyan made a popular and indisputable innovative contribution into trearury of professional pedagogics in terms of defining the structure of self-dependent research activity, the core components of which are the following:

- motivational - value component is characterized by the system of motives which are reflected in the interests, values, life goals, views, ideals making the foundation of the personality, this component determines final efficiency of selfdependent research activity, its orientation onto the optimization of future teachers professional development;

- contextual component is represented by a system of segments and blocks where theoretical information covers all types of scientific material, subject to self-dependent research; practically oriented information guides the student to empirical research of mentioned aspects in their concrete application through the prism of didactically-educational and teaching-educational means;

- processual-operational component presupposes acquiring of scientific search operational-activity mechanism by the student, actualization of knowledge about peculiarities and nature of research actions, their hierarchy;

- reflective component represents self-development, selfprojection and self-realization of a student as a specialistresearcher [7, 65].

As a theoretical ground for understanding this problem and working out methodological fundementals of a future teacher developing scientific competence may be taken 
achievements of pedagogical conception in terms of the specialist functional purpose.

Considering the maturity of teacher's scientific competence as an indicator of his readiness for the realization of scientific and research activity, the scholars decisively prove that it is connected with different aspects of this activity, peculiar properties of which determine the component structure, namely:

- cognitive component in the structure of scientific competence presupposes the ability for active cognition, intellectual activity in the sphere of education, its effectiveness; it is determined by the capability to regulate realization of research and experimental actions, to analyse events and procedures of the environment from the point of view of modern educational conceptions and requirements of a teaching facility;

- diagnostic component includes knowledge and skills to evaluate and correct results of the scientific-pedagogical research; to study and give explanation to the problems which require a new solution; it is also a capability to create an experimental methodology, to predict potential risks and to find ways for coping with them, it is an observance or extention of deadlines for working out and implementation of innovations;

- designing component - skills in programming, modelling, structurization, schematization; it comprises the skills to logically create innovations, to set algorithms of their implementation and planning their experimental approbation; it is a capability to define assessment criteria for expert evaluation of innovations, a skill to determine practical significance of research results and appliance of innovations in specific pedagogical and educational processes; to make a correlation of results and foresee the perspectives of further researches and introduction of changes [2, 23-24].

\section{RESEARCH METHODOLOGY}

Thus, as a result of deep understanding and comparison of different scientific approaches to define the structure of students' research activity in the university, we determined the component structure of future teachers readiness for the scientific research activitity, including motivationalpurposeful, personal, operational-activity and reflexive components, each of which is characterized by a certain content.

Motivational-purposeful component is a dominant element in the structure of scientific and research activity of future teachers which may ensure orientation of the personality to the search, inducing the recognition of your possibilities, your mission, persistence in achieving goals, habit for tireless and meticulous work.

Judging by the theory of the psychologist I. Rusinka, such a dominant "must become the attraction center for all the thinkable and unthinkable man powers, absorb these powers, spin all "the stuffing" of the psycho as if it is a centrifuge, grind its content, cast as if a true steelworker, create a mess in the form required only for this dominant" $[19,50]$.
We are referring here to such a systematic research professional preparation of a future teacher as his conscious rise to vitacultural growth with orientation to effective achievement of results, with a positive experience inheritance of scientific and research work, extension of knowledge range as one of the prior approach to optimization of awakening education. It is necessary to note that full-scale purposefulrational development and self-improvement of a teacherresearcher may become reality only in case of awakening his internal source-regulator (a motive) which determine human activity.

Academic psychologists [12], [18], who consider motivational aspects of the personality, underline that the driving motive of human behavior is stimulating-motivational sphere as a requirement of high level which rouses its orientation, activity, directions, social roles, character, emotions etc.

The category "motivation" is defined by a number of researches-psychologists as: a process keeping mental activity of the person on a certain level at each specific point of time [12, 268]; a dynamic category which contains not only motives but also requirements determining the personality behavior in some social situation and to a certain extent they may be defined as a readiness to act in a definite way in order to achieve the desired goal on the basis of understanding the value of obtaining success and estimation of personal capabilities and efforts, for this purpose it is necessary to apply them in conjunction $[1,6]$; intentions which arouse the activity of the organism determining its orientation [21, 293].

Taking into consideration the opinions of academic psychologists, we must mention that hierarchic composition of a future teacher motivation basis must become a strategic position, with reference to which there must start an experimentally oriented pedagogical process with an aim to awaken among education subjects the positive internal potentials, the inner ramrod, the core of the teacher-researcher personality, activating them in an effective searchinvestigative work.

According to the structure of developing the readiness of future teachers we should point out that this readiness is achieved on the assumption of purposeful subject-to-subject cooperation of educational process participants on the basis of ethical principals through activization of research activity motives because the stimulating-motivational sphere play the leading role as a source of scientific potential of the personality.

For that reason, the motivational-purposeful component, which we pointed out in the structure of future teachers readiness for scientific-research activity, is characterized by their moral-and-value attitude towards their profession; by future teachers' recognition of the significancy and by development of cognitive interest to scientific-research activity; by active-and-positive relation to search occupation as a personal value; by concordance of personal goals with scientific-research work; by stimulating research occupation; by everlasting internal motivation of the personality with reliance on the dominant of practice-oriented pedagogical activity; by performing professional duties in accordance with 
the ethics code of a scientist; by a stable requirement and persistence in search of effective ways to solve professional tasks by means of scientific-and-research work in educational establishments; and by energy in self-development.

Acknowledging the problem of the personality as a matter of priority, we should give a thorough consideration to the demands placed on teachers by the society. The personal component of future teachers' readiness for scientific-research activity, which we singled out in its structure, reveals the peculiarities and role of a teacher-researcher in the context of a new-type modern school innovative development, an important place is taken by humanistic essence of their research training.

Modern scientists draw special attention to the fact it is exactly searching the ways for realization of humanistic pedagogics and the possibility to humanize the educational process which must become a unique axiological foundation stone of the professional students' content. It should be observed in developing a moral and responsible personality of a future teacher-researcher who must be open for further progression and self-evolution, and in the course of time it will certainly lead to the entire humanitarization of the educational process [15], [22].

Thus, the value-rational approach to professional training of morally responsible future teachers stimulates them to the priority of value orientations which are more typical for the growth of spiritual dimension as a backbone factor of pedagogical humanocentrism.

Summarizing, we can mention that in accordance with the principles of humanistic pedagogics the priority guidelines in the research educational environment will be:

- creation of a value-oriented environment, its orientation on;

- formation of the humanly developing subject-to-subject cooperation on the basis of moral and ethical pedagogics, development of cooperative relationships;

- spiritual-axiological richness of school subjects content, specificity and optimization of culturological orientation of educational process, in general;

- respect for the personality of each child, his views, principles and decisions, respect for his freedom and dignity, recognition of his right to be unique;

- enrichment and extension of each pupil spiritual sphere.

The modern teacher today must "stand" on four surfaces, namely: "teacher-personality", "teacher-professional", "teacher-educator" and "teacher-scientist". Generally known fact that a teacher as a personality must be the carrier of high spiritual and moral culture, must be disciplined, conscientious, kind-hearted, responsible, honest and fundamental, also openminded, ready for collaboration, with a good sence of delicate humour, self-sacrifying in work.

A teacher-professional is a highly educated tutor with a high level of professionalism, art of teaching and professional competence, capable of making creative solutions and enriching his intellectual experience, he is autonomous in professional perception, with deep and overall intention for self-knowledge, self-development and self-realization.

As an educator, a teacher must feel love for children, easily come in contact, evoke positive emotions among talk partners, be empathic, delicate, just, observant, sympathetic, organized, reputable, not indifferent to students' lives, with a firm belief in his wards, and be patient.

And finally, a teacher as a scientist is a specialist that day-to-day embodies the principle of scientificity in his teaching practice: training students on the basis of scientific achievements of pedagogics, innovative teaching methods, best pedagogical practices, recommendations for scientific organization of pedagogical work; application of inductivedeductive teaching methods which allow to understand something specific better; reflexion of scientific cognition methods; use of scientific vocabulary; development of critical thinking and logic among students, gradually leading them to searching and creative work while education.

So, taking the above mentioned into consideration, let's make a conclusion that the mission of a modern teacher is evolutionizing in the direction from the transmitter of knowledge to the teacher-adviser, facilitator, tutor, guide, guardian, to a kind-hearted and sympathetic teacher-curator.

It is necessary to note that for the effective modelling influence of the teacher on the student's personality very significant is the choice of character and logic of education subjects spiritually developing cooperation composition in professional training of future teachers. This means professional-pedagogical communication as a strategic reference point of experience-oriented education.

Researchers of communication theory prove that communication allows successfully and purposefully to realize a set of measures for forming a harmoniously developed personality of students, to the maximum facilitating herewith the students' moral transformation.

"As a leading determinant of the whole psychical processes system, states of the person, communication becomes the primary tool for carrying out pedagogic influences on the personality and in case of necessity for optimization and correction of her psychological content", concludes I. Bekh [2, 250].

It needs saying that communicative competence of a teacher must be particularly built on the basis of spiritually developing communication in the context of participants' cooperation as equal partners, the foundation of which will be mutual sociability and acceptance of each other as a unique personality. That is why one of the main priorities in the process of training future teachers for scientific-research activity is spiritually enriched professional-pedagogical communication.

Thus, the content of future teachers' readiness personal component for scientific-research activity is characterized by acceptance of the pupil's personality as the supreme pedagogical value; personal-humane dominant in the research educational environment; system of personal-professional 
attributes required for the realization of research activity; professional-pedagogical communication as a strategic focus of experience-oriented education.

Successful scientific and research activity of future teachers is impossible without the established system of special knowledge and skills, capabilities, modes of acion which will grant them an opportunity to carry out professional duties on a high quality level, therefore the necessity of pointing out the operational-activity component if beyond dispute.

On the assumption that research skills form the basis for the above mentioned component, it seems reasonable to give this aspect a more detailed consideration.

In scientific-pedagogical studies there are several conceptions of knowledge development: conception of developing intellectual knowledge and skills; conception of stagewise formation of mental efforts; conception of transforming competences into skills; conception of transforming skills into competences etc. The most commonly used is the conception of mental efforts and research skills stagewise formation. The stages of developing mental activity methods base themselves upon the structure of cognitive work established in psychology: purpose - motive - example operation - result - correction [23,24].

Research skills of future teachers are represented by a set of practical actions which ensure the capability of the personality to consciously perform search, selection, analysis, design and preparation of intellectual activity results.

It is necessary to underline that operational-activity component of future teachers' readiness for the scientific research work is primarily connected with presence and usage of diagnostic, design and productive skills gained by the students while studying psychological-pedagogical and methodic subjects and also during teaching practice.

This approach is given special interest due to such a composition of the specialist vocational training system that its quality is strategically connected with orientation of a future teacher towards implementation into practice of his abilities to plan, analyze, correlate and compare facts, events, poits of view, conceptions, to find out cause-and-effect relationships; his skills to observe, collect, organize and handle data, make hypotheses, identify a problem, see different approaches to its solution by means of scientific-andresearch work etc.

Consequently, the content of future teachers' preparedness operational-activity component for the scientificresearch activity is characterized by the maturity of knowledge and skills to apply scientific inquiry methods for successful solution of professional issues and tasks; by being aware of modern technologies and methods of research education; by knowing the specific character of arranging and carrying out research activity in the course of teaching academic subjects.

The above-mentioned reflexive component of future teachers' readiness for scientific work first of all consists of their capability to make a very thoughtful analysis of their own occupation, conscious control over results of their professional actions, self-esteem of research attitude, understanding of their own research actions in the context of cooperation with other participants of educational process and finally it includes critical reflection over their own way of living.

In general, development of a future specialist as an intellectual and competent personality, what is realized in the context of pedagogical profession and research orientation high motivation, certainly presupposes the process of goal setting within the scope of action if required, or in other words - reflexion.

It is necessary to note that judging by the theory of L. Vygotskiy [4], reflexive analysis of activity is not the process which is close in "individual space" of self-awareness, just the other way round, general and social psychology studies the capability of the person to treat himself and his activity in a reflexive manner, the result of acquiring by the personality the social relationships between people (interirization). Only on the basis of their cooperation with other people, when the person tries to understand another man's inner world, he relates reflexively to himself.

Relying on the opinion of the scientists [6], [2], [13], we have all reasons to insist that deep reflexion, made by the subject of education, requires active analytico-synthetical activity: panoramic meaningfulness of the research content, peculiarities and successive steps of scientific-and-research activity, meticulous work with one's own consciousness, comparison of "Me - real" with "Me - ideal", self-criticism with an aim to achieve conformity between the goals of personal research behavior.

It needs mentioning that development vectors of the studied readiness reflexive component are sense bearing selfcognition, self-observation, self-determination, self-projection and self-control. Despite all this, it is necessary to take one critically important fact into consideration: in the context of systematic speculation there happens developing of future teachers deep personal-professional reflexion.

We can find the confirmation of this thesis in the monograph of M. Knyazyan who points out that "selfrevelation, self-projection, self-realization facilitate stabilization of the students' independent research activity, continuality and dynamism of its functioning, identification of its future evolution $[7,91]$.

Speculating in a similar manner, we came to the conclusion that the reflexive component of the above mentioned preparedness is represented by displaying exploratory activity; by perception of oneself as a professional researcher on the basis of self-cognition, self-analysis and selfesteem; by self-regulation of behavior; by ability to direct one's activity towards oneself, towards own peculiarities of self-realization; by determining the ways of one's own perspective becoming a researcher; by composition of the selfdevelopment strategy and specific means of its realization; prognosis of short- and long-term results of their implementation. 
IV.

RESULTS

We should notice that the detailed analysis of future teachers' structural components readiness for scientific-and- methods for successful solution of professional issues and tasks; awareness of modern technologies and methods of research education; knowing the specific character of

arranging and carrying out research activity in the course

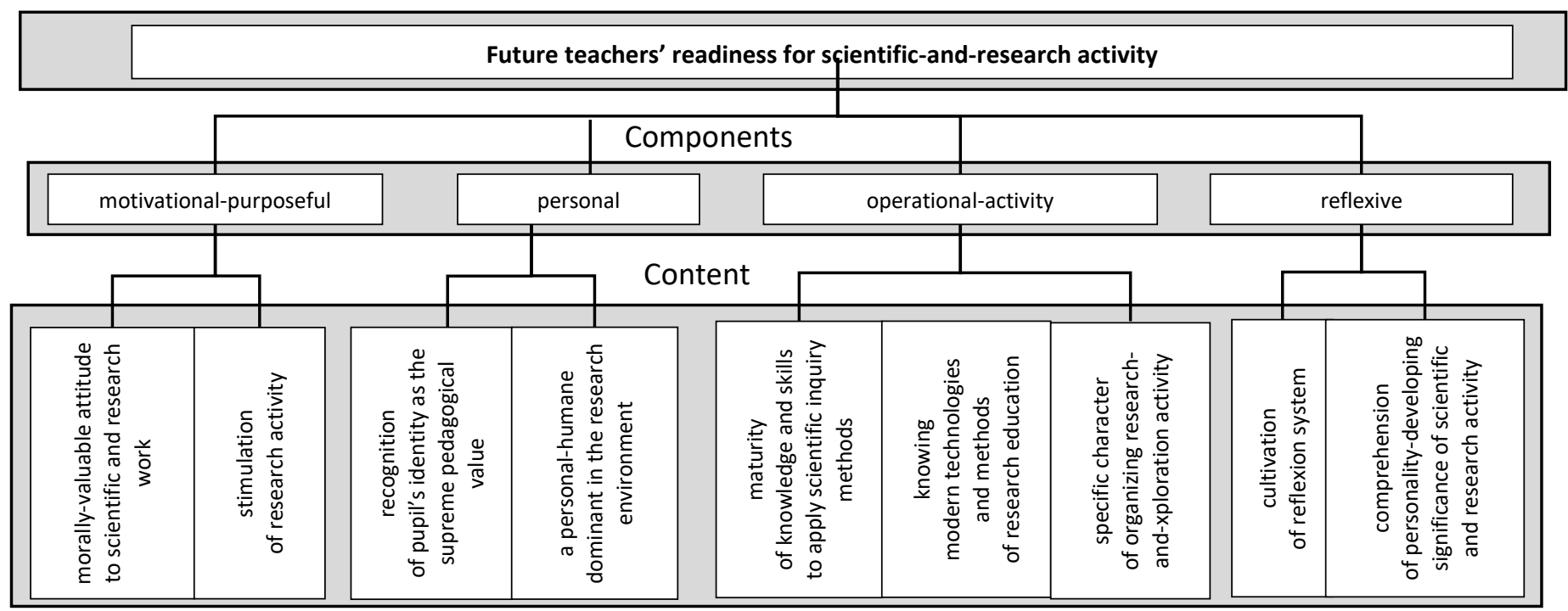

research activity and their contents, shown above, allows us to express it schematically (fig. 1).

Fig. 1. Component structure of future teachers' readiness for scientific-andresearch activity

So, we found out the essence of a key construction "preparedness of future teachers for scientific and research activity", determined by us as an integrative complex of personal qualities, acquired during professional training, and capabilities for successful solution of professional tasks and situations means of scientific search methods; it consists of interconnected components: motivational-purposeful, personal, operational-activity and reflexive components.

\section{DISCUSSION}

The motivational-purposeful component is represented by moral-and-value attitude towards profession; by activeand-positive relation to search occupation as a personal value; by stimulating research activity; by performing professional duties in accordance with the ethics code of a scientist; by a stable requirement and persistence in search of effective ways to solve professional tasks by means of scientific-and-research work in educational establishments; and by energy in selfdevelopment.

The personal component of future teachers' readiness for the scientific research work consists in recognition of pupil's identity as the supreme pedagogical value, personal-humane dominant in the research educational environment; system of personal-professional attributes required for the realization of research activity; professional-pedagogical communication as a strategic focus of experience-oriented education.

The operational-activity component of future teachers' preparedness for the scientific-research activity presupposes the maturity of knowledge and skills to apply scientific inquiry of teaching academic subjects.

The reflexive component of future teachers' preparedness for research activity is characterized by demonstrating exploratory activity; by perception of oneself as a professional researcher on the basis of self-cognition, selfanalysis and self-esteem; by self-regulation of behavior; by ability to direct one's activity towards oneself, towards own peculiarities of self-realization; by determining the ways of one's own perspective becoming a researcher; by composition of the self-development strategy and specific means of its realization; prognosis of short- and long-term results of their implementation.

\section{CONCLUSION}

Thus, we determined and gave scientific justification to the component structure of future teachers' readiness for research activity, including motivational-purposeful, personal, operational-activity and reflexive components; each of them is characterized by a specific content.

\section{References}

[1] Alekseyenko T.F. Motivation of social behavior and mechanisms of its formation. Social pedagogics: theory and practice. 2011, 4, pp.4-10.

[2] Bekh I.D. Personality development: textbook. Kiev: Lybid. 2008, 848

[3] Bondarenko L.I. Formation of research competence of future teachers of higher educational establishments in the context of magistracy. Candidate's thesis. Starobelsk. 2015, 247.

[4] Vygotsky L.S. Problems of general psychology: in 6 volumes. Moscow. 1982-1984, vol. 2, 504.

[5] Durai-Novakova K.M. Development of professional readiness of students for pedagogical activity. Doctor's thesis. Moscow. 1983, 32.

[6] Zaika E. Zimovina A. Reflexity of the personality as a subject of psychological cognition. Psychology and Society. 2014, 2, pp. 90-97.

[7] Knyazyan M.O. Independent research work as a means of preparing the students for solution of problem issues in professional activity. Theory and methods of teaching and education: collection of scientific papers. Kharkov. National Pedagogical University n.a. G.S. Skovoroda. 2012, pp. 97-107. 
[17] Romanovskaya I.A. Formation of research attitude of future teachers in the conext of professional-pedagogical development. Candidate's thesis. Astrakhan. 2006, 162.

[18] Rubinshtein S.L. Theoretical issues of psychology and the problem of personality. Psychology of personality: chrestomathy. Samara: Bakhram. 1999, vol. 2, pp. 227-244.

[19] Rusinka I. Psychology: work book. $2^{\text {nd }}$ edition, updated and revised. Kiev: Znaniye. 2011, 407.

[20] Slastyonin V.A., Isaev I.F., Shiyanov E.N. Pedagogics: work book for students of higher pedagogical educational establishments. Moscow: Akademiya. 2002, 576.

[21] Shapar V.B., Rossokha V.E., Shapar O.V. The newest psychological dictionary. Rostov-on-Don: Pheniks. 2007, 806.

[22] Ivanova N. The phenomenon of spiritual in dimensions of irrational: the context of intuition and faith. Psychology and society. 2016, 3, pp. $6-12$.

[23] Alexsandr S. Kuznetsov. Russian Professor's meeting. Russian Journal of Physical Education and Sport. 2019, 14(1), pp. 17-22. DOI: 10.14526/2070-4798-2019-14-1-18-24

[24] Sushchenko L. The experimental program updates on the quality of professional training of future teachers by means of research. Sciencse and studiy. Pedagogical Sciences, philology. 2013, 27(95), pp. 118122 . 